\title{
The influence of ApoE genotype on the lipid profile and lipoproteins during normal pregnancy in a Southern African population.
}

\author{
Donald Moshen Tanyanyiwa ${ }^{1,2}$, Adrian David Marais ${ }^{3}$, Pamela Byrnes ${ }^{3}$, Sheena Jones ${ }^{3}$
}

\begin{abstract}
1. Division of Human Genetics, Department of Pathology and Institute of Infectious Disease and Molecular Medicine, Faculty of Health Sciences, University of Cape Town, Anzio Road, Observatory, Cape Town, South Africa.

2. Division of Chemical Pathology, Department of Pathology, University of Witwatersrand/ National Health Laboratory Services, Chris Hani Baragwanath Academic Hospital, Johannesburg, South Africa.

3. Department of Internal Medicine, University of Cape Town, Cape Town, South Africa.
\end{abstract}

\begin{abstract}
Background: Pregnancy is associated with increases in fasting triglycerides and total cholesterol. ${ }^{1}$ ApoE isoforms are known to influence the concentration of cholesterol, with apoE2 homozygosity lowering and apoE4 homozygosity raising the cholesterol concentration compared with E3 homozygosity. ${ }^{2}$ The lipid profiles ApoE status and prevalence of small dense LDL species were evaluated for subjects attending an antenatal clinic.

Results: Samples from 690 women aged between 16 and 42 years of age were analyzed during and after pregnancy. The fasting plasma triglyceride concentration (in mmol $/ \mathrm{L}$ ) was significantly higher in pregnancy (median $=1.5, \mathrm{IQR} 1.0-2.0 \mathrm{vs}$ median $=0.6$, IQR 0.5-0.8 respectively, $\mathrm{p}<0.0001$ ). Similarly, the total cholesterol (in $\mathrm{mmol} / \mathrm{L}$ ) was increased during pregnancy (median=4.1, IQR 3.6-4.7 vs median 3.5, IQR 3.1-3.5, respectively $\mathrm{p}=0.0167)$. The median LDL cholesterol and HDL cholesterol did not change. Higher proportions of small density LDL species were seen during pregnancy compared to after pregnancy. The distribution of the LDL species during pregnancy and 6 weeks post-partum were significantly different $\mathrm{p}<0.0001$ with the smaller species being much higher during pregnancy.

Conclusion: ApoE4 genotype was associated with increased total cholesterol and LDL cholesterol concentrations during pregnancy. Pregnancy results in a reversible remodeling of LDL to smaller species, the significance of which is unknown but may indicate a predisposition to atherosclerosis
\end{abstract}

Keywords: Apolipoprotein E. Lipids, pregnancy, small dense LDL species, African.

DOI: http://dx.doi.org/10.4314/ahs.v16i3.28

Cite as: Tanyanyiwa DM, Marais AD, Byrnes P, Jones S. The influence of ApoE genotype on the lipid profile and lipoproteins during normal pregnancy in a Southern African population. Afri Health Sci 2016;16(3): 853-859. DOI: http:/ / dx.doi.org/10.4314/ahs.v16i3.28

\section{Introduction}

The increased metabolic demands for the mother and foetus during pregnancy results in the overproduction of very low density lipoprotein cholesterol (VLDLC) by the liver as reflected by hypertriglyceridaemia and con-

\section{Corresponding author: \\ Donald Moshen Tanyanyiwa, \\ Division of Human Genetics, \\ Department of Pathology and Institute \\ of Infectious Disease and Molecular Medicine, \\ Faculty of Health Sciences, University of Cape Town, \\ Anzio Road, Observatory, Cape Town, South Africa. \\ Email: donaldmoshen@gmail.com, \\ donald.tanyanyiwa@wits.ac.za}

sequently the remodeling of LDL to smaller, denser particles. $^{3-5}$ When there is a hindrance of clearance of remnants of the triglycerides (TG)-rich lipoproteins or of lipolysis by genetic defects in apoE and lipoprotein lipase (LPL), dyslipidaemia and severe hypertriglyceridaemia may occur during pregnancy. Apolipoprotein E (ApoE) facilitates the binding of lipoprotein particles to the LDL receptor and heparane sulphate and proteoglycans $^{6}$ and the $\varepsilon 4$ allele has been associated with increased total cholesterol and consequent high risk for ischaemic heart disease in men. ${ }^{7-9}$ Similar changes can be expected in women. However, the prevalence of ApoE alleles has been reported to vary in different populations ${ }^{10}$ but this genetic feature is not expected to be altered by pregnancy (See table 1). 
In addition, there is a paucity of evidence on the effect of Apo E genotype on cholesterol subfractions during pregnancy.

While a high TG concentration has been associated with an increased risk of coronary heart disease ${ }^{11,12}$, the gestational increase in TG is also associated with changes in the size of low density lipoproteins (LDL), with a gradual increase in the proportion of the smaller, denser species. ${ }^{3,12}$ The smaller dense LDL species have been found to be atherogenic, ${ }^{13}$ possibly through their contribution to endothelial dysfunction as they are more easily oxidized ${ }^{14,15}$ and are less easily recognized by the LDL receptor, thereby staying in the plasma compartment longer. ${ }^{12}$ Another feature of the small dense LDL species that adds to their high atherogenicity is that they are more readily taken up by macrophages, creating foam cells. ${ }^{12,14}$

Most pregnant mothers display the physiologic TG increases during pregnancy which is probably not atherogenic given that there is compensation by an equal increase in high density lipoprotein (HDL) which ${ }^{3,16}$ could provide benefit by reverse cholesterol transport ${ }^{17,18}$ antioxidant properties, ${ }^{18}$ anti-inflammatory properties ${ }^{19}$ and anti-aggregatory effects on platelets. ${ }^{20}$ However, pregnancy may precipitate significant hypertriglyceridaemia in susceptible individuals. This may be a risk for those with multiple pregnancies..

In this study we investigated the prevalence of dyslipidaemia as well as the distribution of the small dense LDL species in pregnant women with different ApoE genotypes. We hypothesized that carriers of the ApoE4 genotype were more likely to have: 1) dyslipidaemia and 2) higher proportions of the small dense LDL species

\section{Materials and methods Design and Setting}

This cross-sectional study, performed between January 2002 and December 2002 involved normal normotensive pregnant (diagnosed via clinical and ultrasound findings) women of age 16-45 years. The women were recruited from two busy primary health care centres (Mbare and Mabvuku Polyclinics in Harare) during their scheduled antenatal appointments. All women who were able to consent and participate during and after pregnancy were included in the study provided they were not diabetic before or during pregnancy. Women with known complicated pregnancies were referred to tertiary care centres and not included in the study. In addition, women on lipid lowering drugs were excluded.

\section{Sample collection, lipid measurements and APOE genotyping}

Fasting venous blood samples were taken 2 times during pregnancy and 6 weeks after pregnancy. The blood samples were collected in 5ml EDTA (dipotassium ethylenediaminetetraacetic acid) containing tubes, centrifuged and the blood and serum were separated and stored frozen at minus $40^{\circ} \mathrm{C}$ until assayed. Direct conventional enzymatic spectrophotometric methods, using the Roche Modular Auto-analyser, were employed to derive plasma triglyceride (TG), total cholesterol (TC)and high-density lipoprotein cholesterol concentrations (HDLC) while LDL cholesterol was calculated using the Friedewald formula. Genotyping of apolipoprotein E (ApoE), using the buffy coat, was done by polymerase chain reaction as published by Hixson and Vernier, ${ }^{21}$ using the forward primer 5'GAGACGCGGGCACGGCTGTC-3' and the reverse primer 5'-GGGCCCCGGCCTGGTACACT-3'.

\section{LDL species measurement}

Non-denaturing gradient gel electrophoresis, using a Biorad was employed to classify LDL species into 5 categories named A, AI, I, IB and B in decreasing sizes. Briefly, after thawing overnight, pre-stained (using Sudan Black Stain) lipoproteins in plasma were run at $4^{\circ} \mathrm{C}$ in a nondenaturing gradient 3-8\% gel sandwiched between 2 glass plates. The lipoproteins were separated according to size in a gel in which the concentration of acrylamide increased progressively. The gel was designed to separate all ApoB-containing lipoproteins. The small particles like LDL-B migrated furthest in the gel because the sizes of pores decrease with an increase in acrylamide content. The gels were removed at the end of the run and excess fluid/buffer was blotted from the glass slides and the gels were photocopied onto a white paper for reporting and record keeping. Direct gel interpretation was made by blinded Lipidologists.

The gel terminology was derived to describe the lipoproteins corresponding to the particles separated and calibrated by ultracentrifugation. The origin of the separation gel represents 0 and the migration of small dense represents 1,0 and all lipoproteins in this gel system were calibrated by ultra-centrifugally prepared samples. Chy- 
lomicrons appear at the origin, Rf $0-0.15$ termed as $\mathrm{O}$. LDL 1 appeared between - and 0.15 and was referred to as Me while LDL2 was between - and -, referred to as MI. IDL was between Rf 0-085 and in this system included Lp(a). This range was called pre A. The LDL traction ranged from $\operatorname{Rf}$ 0.85- 1.0 displaying for most subjects a single or highly dominant discrete band. The largest was designated "A" and the smallest "B". An "I" species was identified in the middle and further categories of "AI" and "M" were also identified.

\section{Statistical data analysis}

All continuous data was tested for Normality using Shapiro Wilks test, with significance set at $\mathrm{p}<0.05$. LDL species prevalence during pregnancy and was compared to that after pregnancy using chi squared and Fisher's exact tests. Lipid concentrations during and after pregnancy were compared using t-tests and their non-parametric equivalents as appropriate. Chi squared test was used to compare LDL species frequencies and proportions between the ApoE genotypes, whose frequencies were determined by gene counting. The differences in the LDL species and lipid profiles among the ApoE genotypes were compared using the Kruskal Wallis test. For all statistical analysis, level of significance was set at $\mathrm{p}<0.05$.

\section{Ethical Considerations}

Ethical approval for the study was sought from and granted by the University of Cape Town Human Ethics Research Committee and the Medical Research Council (MRC) of Zimbabwe. All participants signed a written informed consent before taking part in the study.

\section{Results}

A total of 690 women were recruited during the period January 2002 to December 2002. Due to loss to followup, only 472 who had data available during and after pregnancy were included in the final analysis. The median age of the participating women was 24 years (IQR 20 28 years), the youngest being 16 and the oldest being 42 years of age. The median gestational age at the time of collection of the first sample (during pregnancy) was 29 weeks (IQR 27 - 32 weeks): the earliest being 13 weeks and the latest being 38 weeks.

\section{Table 1: Comparison of apoE genotype and allele frequency between pygmies and Africans}

\begin{tabular}{|l|l|l|}
\hline Genotype & Pygmies & Africans \\
\hline ApoE2/2 & 0 & 2.3 \\
\hline ApoE2/3 & 7.2 & 14.3 \\
\hline ApoE2/4 & 4.3 & 4.3 \\
\hline ApoE3/3 & 27.1 & 52.1 \\
\hline ApoE3/4 & 45.7 & 22.8 \\
\hline ApoE4/4 & 15.7 & 4.3 \\
\hline Allele & & \\
\hline Apos2 & 5.7 & 11.6 \\
\hline Apos3 & 53.6 & 70.6 \\
\hline Apos4 & 40.7 & 17.8 \\
\hline
\end{tabular}

Zekraoui et al 1997. Table 1 shows that apos3 is the most predominant allele in the two groups, but apos4 is very high in the pygmies

\section{Prevalence of LDL species during and after preg- nancy}

Table 2 below shows the distribution of LDL species as measured during pregnancy and 6 weeks after pregnancy.
During pregnancy, $38(8 \%)$ of the participants had no clearly definable LDL species, while $14(3 \%)$ had 2 species of LDL and the remainder had a single species. After pregnancy dual species were seen in $9(2 \%)$ while only 1 participant had no clearly defined species. 
There were higher proportions of the small dense LDL species during pregnancy than 6 weeks after pregnancy. During pregnancy distribution in the categories A, AI, I,
IB, B was $2,9,34,45,10 \%$ respectively while after pregnancy the LDL species distribution was: 44, 26, 26, 3 and $1 \%$ respectively, $\mathrm{p}<0.0001$.

Table 2: Prevalence of LDL species during and after pregnancy $(n=472)$

\begin{tabular}{|l|l|l|l|l|l|l|l|}
\hline & A & AI & I & IB & B & Dual & $\begin{array}{l}\text { Species not } \\
\text { clearly defined }\end{array}$ \\
\hline $\begin{array}{l}\text { During } \\
\text { pregnancy, n (\%) }\end{array}$ & $7(1.5)$ & $38(8.3)$ & $153(32.4)$ & $180(38.1)$ & $42(8.9)$ & $14(3.0)$ & $38(8.3)$ \\
\hline $\begin{array}{l}\text { After pregnancy, } \\
\mathrm{n}(\%)\end{array}$ & $\begin{array}{l}203 \\
(43.0)\end{array}$ & $120(25.4)$ & $120(25.4)$ & $15(3.2)$ & $4(0.9)$ & $9(1.9)$ & $1(0.2)$ \\
\hline
\end{tabular}

CONTINGENCY TABLE CHI SQUARED P $<0.001$

\section{ApoE genotypes prevalence and LDL species}

Of the 690 subjects, 678 participants had genotype data available which revealed that the majority were ApoE 3/3, 271 (40\%) followed by ApoE3/4, 175 (25.8\%), ApoE2/3, 118 (17.4\%), ApoE2/4, 48 (7\%), ApoE4/4, 41 (6.1\%) and ApoE2/2, 25 (3.7\%). ApoE genotype did not influence LDL species distribution during pregnancy (A vs I vs $B$, chi squared p-value $=0.33$ ) or after pregnancy (A vs I vs $B$, chi squared $p$-value $=0.33$ ).

The lipid profile changes in pregnancy and ApoE genotype

Table 3 below shows the comparison between plasma lipid median concentrations during and after pregnancy in the whole cohort. The median plasma triglyceride concentration (in $\mathrm{mmol} / \mathrm{L}$ ) was significantly higher in pregnancy, compared to concentration 6 weeks after pregnancy $($ median $=1.5$. IQR $1.0-2.1$ vs. median $=0.6 . \mathrm{IQR}$ $0.5-0.8$ respectively, $\mathrm{p}<0.0001)$. The median TC was significantly higher during pregnancy, compared to the TC 6 weeks after pregnancy (median $=4.1 . \mathrm{IQR} 3.6-4.7$ vs median 3.6.IQR 3.1 - 4.0, respectively p<0.0001).

The median LDL cholesterol concentration during and after pregnancy did not change significantly (Table 3). Similarly no significant differences in median HDL cholesterol during and after pregnancy were observed (Table 3).

Table 3: Comparison of lipid changes during pregnancy and 6 weeks after pregnancy $(n=472)$

\begin{tabular}{|l|l|l|l|l|l|}
\hline & & TC & TG & LDLC & HDLC \\
\hline During pregnancy & Median $(\mathrm{mmol} / \mathrm{L})$ & 4.1 & 1.5 & 2.0 & 1.3 \\
\hline & IQR $(\mathrm{mmol} / \mathrm{L})$ & $3.6-4.7$ & $1.0-2.1$ & $1.8-2.4$ & $1.0-1.6$ \\
\hline After pregnancy* & Median $(\mathrm{mmol} / \mathrm{L})$ & 3.6 & 0.6 & 2.0 & 1.2 \\
\hline & IQR $(\mathrm{mmol} / \mathrm{L})$ & $3.1-4.0$ & $0.5-0.8$ & $1.6-2.0$ & $0.9-1.4$ \\
\hline & Mann Whitney $\mathrm{p}-$ value & $<0.01$ & $<0.001$ & 0.16 & 0.167 \\
\hline
\end{tabular}

* MEASURED AT LEAST 6 WEEKS AFTER DELIVERY 
Table 4 shows the lipid concentrations according to the various ApoE genotypes during pregnancy. Median (TC) was higher in women with the ApoE4/4 genotype (median = 4.3, IQR 3.7-5.0) and ApoE3/3 (median = 4.2, IQR 3.5-4.7) compared to that of women with ApoE2/2 genotype $($ median $=3.5$, IQR 3.3-4.5), $\mathrm{p}=0.06$. Median
LDLC was higher in women with the ApoE 4/4 (median $=2.3$, IQR 1.9-3.1), ApoE3/4 (median = 2.0, IQR 1.62.6) and ApoE $3 / 3$ (median $=2.0$, IQR 1.6-2.6) when compared to the median LDLC concentration of women with the ApoE2/2 genotype (median = 1.5, IQR 1.2-2.6), $\mathrm{p}=0.02$.

Table 4: Correlation between ApoE genotypes and lipid concentrations

\begin{tabular}{|l|l|l|l|l|}
\hline $\begin{array}{l}\text { ApoE } \\
\text { Genotype }\end{array}$ & $\begin{array}{l}\text { TC } \\
\text { Median(IQR) }\end{array}$ & $\begin{array}{l}\text { TG } \\
\text { Median(IQR) }\end{array}$ & $\begin{array}{l}\text { LDLC } \\
\text { Median(IQR) }\end{array}$ & $\begin{array}{l}\text { HDL } \\
\text { Median(IQR) }\end{array}$ \\
\hline $\begin{array}{l}\text { E2/2 } \\
(\mathrm{n}=14)\end{array}$ & $\begin{array}{l}3.5 \\
(3.3-4.5)\end{array}$ & $\begin{array}{l}1.5 \\
(1.0-2.3)\end{array}$ & $\begin{array}{l}1.5 \\
(1.2-2.6)\end{array}$ & $\begin{array}{l}1.3 \\
(0.7-1.6)\end{array}$ \\
\hline $\begin{array}{l}\text { E2/3 } \\
(\mathrm{n}=94)\end{array}$ & $\begin{array}{l}4.1 \\
(3.4-4.4)\end{array}$ & $\begin{array}{l}1.3 \\
(1.0-2.0)\end{array}$ & $\begin{array}{l}1.9 \\
(1.6-2.3)\end{array}$ & $\begin{array}{l}1.4 \\
(1.1-1.6)\end{array}$ \\
\hline $\begin{array}{l}\text { E2/4 } \\
(\mathrm{n}=40)\end{array}$ & $\begin{array}{l}3.9 \\
(3.4-4.7)\end{array}$ & $\begin{array}{l}1.3 \\
(0.9-1.7)\end{array}$ & $\begin{array}{l}1.9 \\
(1.6-2.6)\end{array}$ & $\begin{array}{l}1.3 \\
(1.1-1.5)\end{array}$ \\
\hline $\begin{array}{l}\text { E3/3 } \\
(\mathrm{n}=223)\end{array}$ & $\begin{array}{l}4.2 \\
(3.6-4.7)\end{array}$ & $\begin{array}{l}1.4 \\
(1.0-2.0)\end{array}$ & $\begin{array}{l}2.0 \\
(1.6-2.6)\end{array}$ & $\begin{array}{l}1.2 \\
(1.0-1.5)\end{array}$ \\
\hline $\begin{array}{l}\text { E4/4 } \\
(\mathrm{n}=33)\end{array}$ & $\begin{array}{l}4.3 \\
(3.7-5.0)\end{array}$ & $\begin{array}{l}1.4 \\
(1.1-1.9)\end{array}$ & $\begin{array}{l}2.3 \\
(1.9-3.1)\end{array}$ & $\begin{array}{l}1.2 \\
(1.0-1.4)\end{array}$ \\
\hline $\begin{array}{l}\text { All subtypes } \\
\text { Kruskal Wallis } \\
\mathrm{p} \text {-value }\end{array}$ & $0.135^{*}$ & $0.846^{*}$ & $0.021 \dagger$ & $0.187 \pi$ \\
\hline
\end{tabular}

COMPARISON BETWEEN E2/2 VS E3/3 VS E4/4 LIPID CONCENTRATIONS (USING KRUSKAL WALLIS) +P-VALUE FOR LDLC $=0.0196$

There were no significant differences between the ApoE genotypes in the concentrations of triglycerides and high density lipoprotein cholesterol during pregnancy (Table 4).

\section{Discussion}

There are many factors that determine the risk for the development of cardiovascular disease. They include diet, smoking, hereditary factors, age and other comorbidities. ${ }^{16,22}$ The effect of the ApoE gene polymorphisms on risk of cardiovascular disease in normal pregnancies has not been investigated before in this African population. In addition, although the ApoE4 genotype has been associated hypercholesterolaemia and thus with increased risk of cardiovascular disease in studies from Western countries, ${ }^{16}$ its association with distribution of the small dense LDL species during pregnancy is not well described.

We found that the distribution of LDL species was not associated with ApoE genotype, during normal pregnancy. Chikosi et al demonstrated a fivefold higher preva- lence of ApoE2/2 and ApoE4/4 compared to that seen in other populations, although they found that this was not associated with the high levels of dyslipidaemia in the Zulu women studied. ${ }^{23}$ However in this study, they did not measure lipid profiles of the women.

The finding that the small dense LDL species are increased during pregnancy is in agreement with previous findings in other ethnic groups and animal studies., ${ }^{3,24,26}$ Our data also shows that these small dense LDL species are likely physiologic and risk could be counterbalanced by HDL cholesterol increases.

In our study ApoE4 genotype was associated with increased total cholesterol in normal pregnancy. This result agrees with a study in the Limpopo province of South Africa that reported an association between ApoE4 allele with increased total cholesterol, LDLC, HDLC and TG in a non-pregnant population. ${ }^{22}$ Our results differ in that we did not find a significant association between the ApoE4 
allele and both HDLC and TG.Our results indicated that serum cholesterol was within normal parameters in spite of highly increased proportions of small dense LDL species. This finding agrees with the suggestion, that measuring serum apolipoprotein $\mathrm{B}$, instead of serum cholesterol would detect more patients at risk of myocardial infarction. ${ }^{25}$ Apolipoprotein $\mathrm{B}$ is the main protein that makes up LDL. Furthermore apolipoprotein B concentration has been shown to be highly correlated with coronary heart disease events, ${ }^{27}$ so monitoring its concentration may also help in assessing treatment progress in susceptible mothers; however its value has not been studied prospectively in relation its changes in pregnancy. In line with previous studies, ${ }^{3-5}$ our results showed significant increases in TG levels during pregnancy. This change is transient as demonstrated by the decrease in TG concentrations after pregnancy. In addition, we found that ApoE genotype was not associated with changes in the concentrations of TG in normal pregnancy in this African population.

Finally we found that ApoE genotypes prevalence in the Shona population was comparable to that described in a Zulu cohort. ${ }^{23}$ This may be a reflection of the similarities in the populations studied, in that they are both Africans in the same geographical region, Southern Africa. Historically, the Ndebele, descendants of the Zulu migrated to the North and settled in Zimbabwe and there have been inter-marriages between Ndebele and Shona people.

\section{Conclusion}

ApoE genotype in Zimbabwean women in this study does not appear to influence LDL size, although ApoE4 genotype appears to be associated with increases in cholesterol and LDL, compared to other genotypes. Pregnancy is associated with increases in the concentrations of TG, TC and HDL in our population, although LDL does not appear to vary. There is a higher prevalence of small dense LDL species during pregnancy which reverts back to normal in this population.
Abbreviations
ApoE - Apoprotein E
HDL - high density lipoprotein
LDL - low density lipoprotein
LPL - lipoprotein lipase
TC - total cholesterol
TG - triglycerides
VLDL - very low density lipoprotein

\section{Conflict of interest}

None to declare.

\section{Acknowledgements}

We would like to thank during Dr Wellington, Acting Director for City of Harare for granting us permission to conduct the study in Harare. Mrs. Lydia Tanyanyiwa who managed the logistics of sample transportation from the clinics to the medical school, Prof ZAR Gomo for allowing the storage and initial processing of samples in his department. State Registered Nurses Jenami and Maravanyika in charge of Mabvuku and Mbare Clinics respectively managed the recruitment and follow up processes. Mr. Chibi who carried out the initial sample preparation and storage. Dr Mpho Maphayi, Dr Chemedzai Chikomba, Dr Siyabonga Professor Khoza and Dr Brain Gwebu, all Chemical Pathology registrars for polishing the final draft.

\section{References}

1. McGladdery SH, Frohlich JJ. Lipoprotein lipase and apoE polymorphisms: relationship to hypertriglyceridemia during pregnancy. J Lipid Res. 2001 Nov; 42(11):190512.PMID: 11714860

2. Dallongeville J, Lussier-Cacan S, Davignon J. Modulation of plasma triglyceride levels by apoE phenotype: a meta-analysis. J Lipid Res. 1992 Apr; 33(4):447-54. PMID:1388198

3. Belo L, Caslake M, Gaffney D, Santos-Silva A, PereiraLeite L, Quintanilhal A. Changes in LDL size and HDLconcentration in normal and pre-eclamptic pregnancies. Atherosclerosis. 2002 Jun; 162(2):425-32. PMID: 11996963 DOI: 10.1016/S0021-9150(01)00734-1

4. Piechota W, Staszewski A. Reference ranges of lipids and apolipoproteins in pregnancy. Eur J Obstet Gynecol Reprod Biol. 1992 Jun 16; 45(1):27-35. PMID: 1618359

5. Pocovi M, Ordovas JM, Grande-Covian F. Plasma lipids and apolipoproteins A and B in human pregnancy. Rev Esp Fisiol. 1984 Jun; 40 (2):183-9. PMID: 6333054

6. Bangen KJ, Beiser A, Delano-Wood L, Nation DA, Lamar M, Libon DJ, Bondi MW, Seshadri S, Wolf PA, Au R. APOE genotype modifies the relationship between midlife vascular risk factors and later cognitive decline. J Stroke Cerebrovasc Dis. 2013 Nov; 22(8):1361-1369. PMID: 23601373, DOI: 10.1016/j.jstrokecerebrovasdis.2013.03.013

7. Contois JH, Anamani DE, Tsongalis GJ. The underlying molecular mechanism of apolipoprotein E polymor- 
phism. Clin Lab Med. 1996 March; 16 (1):105-23. PMID: 8867586

8. Humphries SE, Talmud PJ, Hawe E, Bolla M, Day IN, Miller GJ. 2001. Apolipoprotein E4 and coronary heart disease in middle-aged men who smoke: a prospective study. Lancet. 2001 Jul 14; 358 (9276):115-9. PMID: 11463413 DOI: 10.1016/S0140-6736(01)05330-2

9. Lahoz C, Schaefer EJ, Cupples LA, Wilson PW, Levy D, Osgood D, Parpos S, Pedro-Botet J, Daly JA, Ordovas JM. Apolipoprotein E genotype and cardiovascular disease in the Framingham Heart Study. Atherosclerosis. 2001 Feb 15; 154(3):529-37. PMID: 11257253

10. Zekraoui L, Lagarde JP,Raisonnier A, Gérard N, Aouizérate A, Lucotte G. High Frequency of the Apolipoprotein $E^{*} 4$ Allele in African Pygmies and Most of the African Populations in Sub-Saharan Africa. Hum. Biol. 1997; 69: 575-81 PubMed . PMID: 9198315

11. Hokanson J, Austin MA. Plasma triglyceride level is a risk factor for cardiovascular disease independent of high-density lipoprotein cholesterol level: a meta-analysis of population-based prospective studies. J Cardiovasc Risk. 1996; 3(2):213-9. PMID: 8836866

12. Packard C. LDL subfractions and atherogenicity: an hypothesis from the University of Glasgow. Curr Med Res Opin. 1996; 13(7):379 PubMed -390. PMID: 8862937 DOI:10.1185/03007999609111557

13. Austin MA, Breslow JL, Hennekens CH, Buring JE, Willett WC, Krauss RM. Low-density lipoprotein subclass patterns and risk of myocardial infarction. JAMA. 1988 Oct 7;260(13):1917-21. PMID: 3418853

14. Witztum JL. Susceptibility of low-density lipoprotein to oxidative modification. Am J Med. 1993 Apr; 94(4):3479. PMID: 8475927 DOI:10.1016/0002-9343(93)90143-d 15. Sattar N, Greer IA, Louden J, Lindsay G, McConnell M, Shepherd J, Packard CJ. Lipoprotein subfraction changes in normal pregnancy: threshold effect of plasma triglyceride on appearance of small, dense low density lipoprotein. J Clin Endocrinol Metab. 1997 Aug; 82(8):248391. PMID: 9253322 DOI: $10.1210 /$ jcem.82.8.4126

16. Lusis AJ. Atherosclerosis. Nature. 2000 Sep 14; 407(6801):233-41. PMID: 11001066 DOI: $10.1038 / 35025203$

17. Gordon DJ, Rifkind BM. High-density lipoprotein--the clinical implications of recent studies. $N$ Engl J Med. 1989 Nov 9; 321(19):1311-6. PMID: 2677733 DOI:10.1056/NEJM198911093211907
18. Parthasarathy S, Barnett J, Fong LG. High-density lipoprotein inhibits the oxidative modification of lowdensity lipoprotein. Biochim Biophys Acta. 1990 May 22; 1044(2):275-83 PMID: 2344447

19. Cockerill GW, Huehns TY, Weerasinghe A, Stocker C, Lerch PG, Miller NE, Haskard DO. Elevation of plasma high-density lipoprotein concentration reduces interleukin-1-induced expression of E-selectin in an in vivo model of acute inflammation. Circulation. 2001 Jan 2;103(1):108-12. PMID: 11136694 DOI:10.1161/01. CIR.103.1.108

20. Khoo JC, Miller E, McLoughlin P, Steinberg D. Prevention of low density lipoprotein aggregation by high density lipoprotein or apolipoprotein A-I. J Lipid Res. 1990 Apr; 31 (4):645-52. PMID: 2112580

21. Hixson JE, Vernier DT. Restriction isotyping of human apolipoprotein $\mathrm{E}$ by gene amplification and cleavage with HhaI. J Lipid Res. 1990 Mar; 31 (3):545-8. PMID: 2341813

22. Masemola ML, Alberts M, Urdal P. Apolipoprotein $\mathrm{E}$ genotypes and their relation to lipid levels in a rural South African population. Scand J Public Health Suppl. 2007 Aug;69:60-5. PMID: 17676504 DOI: 10.1080/14034950701355635

23. Chikosi AB, Moodley J, Pegoraro RJ, Lanning PA, Rom L. Apolipoprotein E polymorphism in South African Zulu women with preeclampsia. Hypertens Pregnancy. 2000; 19(3):309-14. PMID: 11118404

24. Belo L, Caslake M,Santos-Silva A, Castro EM, Pereira-Leite L, Quintanilha A, Rebelo I. LDL size, total antioxidant status and oxidised LDL in normal human pregnancy: a longitudinal study. Atherosclerosis. 2004. 177(2):391-399. PMID: 15530915 DOI: 10.1016/j.atherosclerosis.2004.07.023

25. Durrington P. Dyslipidaemia. Lancet. 2003 Aug 30;362(9385):717-31. PMID: 12957096 DOI: 10.1016/ S0140-6736(03)14234-1

26. Smith JL, Lear SR, Forte TM, Ko W, Massimi M, Erickson SK. Effect of pregnancy and lactation on lipoprotein and cholesterol metabolism in the rat. J Lipid Res. 1998 Nov;39(11):2237-49. PMID: 9799810

27. Ryoo JH, Ha EH, Kim SG, Ryu S, Lee DW. Apolipoprotein $\mathrm{B}$ is highly associated with the risk of coronary heart disease as estimated by the Framingham risk score in healthy Korean men. J Korean Med Sci. 2011 May;26(5):631-6. 26(5): 631-636. PMID: 21532853 DOI: $10.3346 / \mathrm{jkms} .2011 .26 .5 .631$ PubMed

African Health Sciences Vol 16 Issue 3, September 2016 